\title{
A Parallel Processing Uninterruptible Power Supply for Sudden Voltage Fluctuation for Power Management
}

\author{
Sung-Hun Ko, Seong-Ryong Lee \\ Department of Control \& Robot Engineering, Kunsan National University, Kunsan, Korea \\ Email: merchin@kunsan.ac.kr, srlee@kunsna.ac.kr
}

Received 2013

\begin{abstract}
This paper deals with a parallel processing uninterruptible power supply (UPS) for sudden voltage fluctuation in power management to integrate power quality improvement, load voltage stabilization and UPS. To reduce the complexity, cost and number of power conversions, which results in higher efficiency, only one voltage-controlled voltage source inverter (VCVSI) is used. The VCVSI is connected in series on the DC battery side and in parallel on the AC grid side with a decoupling inductor. The system provides sinusoidal voltage at the fundamental value of $220 \mathrm{~V} / 60 \mathrm{~Hz}$ for the load during abnormal utility power conditions or grid failure. Also, the system can be operated to mitigate the harmonic current and voltage demand from nonlinear loads and provide voltage stabilization for loads when sudden voltage fluctuation occur, such as sag and swell. The experimental results confirm the system protects against outages caused by abnormal utility power conditions and sudden voltage fluctuations and change.
\end{abstract}

Keywords: Parallel Processing; UPS; Decoupling Inductor; Power Angle; VCVSI

\section{Introduction}

Computers and automatic equipment are widely used in homes, offices, manufacturing, industrial and commercial applications. With the growth of information systems, internet data centers, on-line banking systems, life support system, and other similar applications, uninterruptible power supply (UPS) are being researched and developed to improve the available power quality for nonlinear loads and to protect critical equipment cause from abnormal utility power conditions, voltage transients, and voltage sag and swell [1-5]. According to the National Power Laboratory (NPL) power quality study [6], voltage sags and under-voltage account for the largest percentage of these disturbances at $59.6 \%$ of the total. Voltage swells, or surges, and over-voltages represent $28.9 \%$ of these disturbances, impulses account for $8.1 \%$, and outages account for the other $3.4 \%$. This shows that load voltage stabilization is the most important issue for power management systems. Hence, it is generally expected that the UPS will perform the following functions [7-9].

1) Load voltage stabilization ( $\pm 5 \%$ voltage regulation) in both normal and abnormal utility power conditions;

2) Supply of clean and uninterrupted power to the loads;

3) Harmonic mitigation (THD < 5\%) in both normal and abnormal utility power condition

Due to the demand for UPS technologies, a considera- ble number of studies have been conducted on high power quality and voltage stabilization beyond the basic function. The on-line UPS using the double conversion principle was commonly used in the 1970s. It consists of a rectifier-charger, battery set and inverter. The charging-rectifiers, charges the battery and supplies the inverter with DC power, and the inverter supplies the load with continuous, precisely regulated AC power. Whether or not the main power supply is normal, an on-line UPS always governs the output voltage without any transfer time and is more reliable. But harmonic and high energy waste from on-line UPSs is becoming an increasing concern to utility engineers and operators of UPS systems. This system must use an extra power device for power factor correction in order to improve power quality. However, this increases the hardware and installation cost of the system and adds additional energy losses. The on-line UPSs dissipate too much power because incoming AC power must be first converted into DC power and then converted back to AC power. Typically, there is a $10 \%$ energy loss during this double conversion process [5,10-11].

The bi-directional VCVSI is able to transfer power flowing between the DC battery and the AC grid in both directions while in either battery charging mode or inverting mode (UPS). The VCVSI provides load voltage stabilization, harmonic mitigation and UPS features $[12,13]$. A parallel processing UPS using a bi-directional 
VCVSI has many advantages over an online UPS. For instance, in a parallel processing UPS the power is not taken via a separate rectifier to a DC bus in the same way as an online UPS. The power is fed directly, via a lossless impedance decoupling inductor, to the battery by controlling the VCVSI phase angle. This means that a parallel processing UPS can offer many advantages over an online UPS, such as higher efficiency, no delay or break in supply load in changing from rectifier to inverting modes, etc.

In this paper, a parallel processing UPS using a bi-directional VCVSI for sudden voltage fluctuation in power management is presented. The main purposes of this system are to compensate the current harmonic and reactive power demand from nonlinear loads, to support the load voltage stabilization during sag and swell voltage fluctuations, and to supply clean and uninterrupted power during abnormal utility power conditions at the point of installation for power distribution to critical loads. In order to verify the proposed system, computer simulation and experimental results are also presented.

\section{System Description and Analysis}

A typical configuration of the parallel processing UPS using a single-phase bi-directional VCVSI is shown in Figure 1. The system consists of a bi-directional VCVSI, a decoupling inductor, $\mathrm{X}_{\mathrm{m}}$, and a battery bank. The VCVSI is synchronized and connected to the grid through the decoupling inductor to prevent large power flows to or from the grid. The VCVSI is connected to the battery, providing bi-directional power for rectification, charging and inversion (UPS) flow capability between the battery and the AC side. The maintenance of the load voltage and power flow of the system is controlled by adjusting the amplitude and phase angle of the VCVSI output voltage, with respect to the grid voltage.

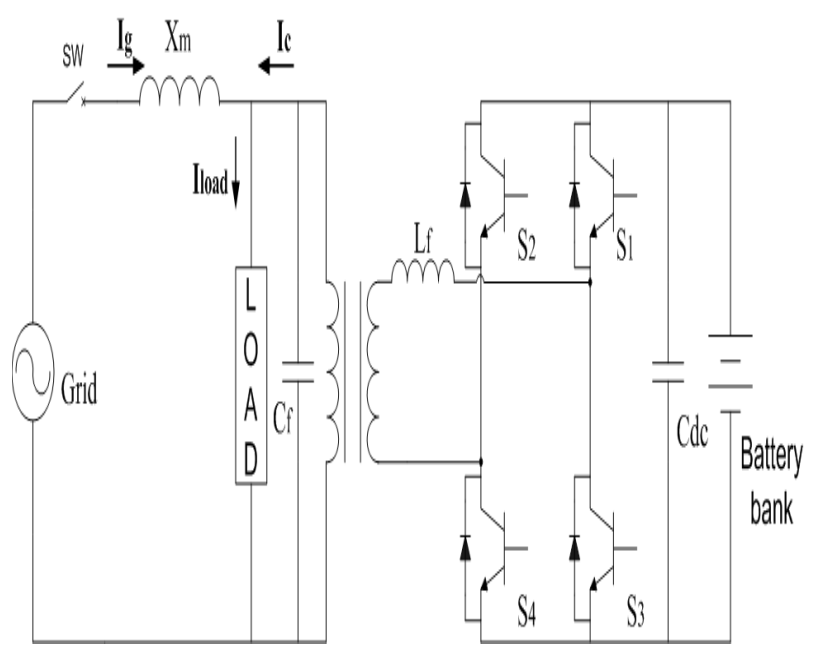

Figure 1. Schematic diagram of a parallel processing UPS.
The system operation has been divided into two modes, normal and UPS. In normal mode, the gird supplies power to load without any power conversion. The VCVSI supplies or compensate the required reactive power demand of the load. The VCVSI produces a constant output voltage across the load by sinusoidal Pulse Width Modulation (PWM). This allows the proposed system to mitigate the harmonic current and voltage demand of nonlinear loads and provide voltage stabilization, when sudden sag and swell voltage fluctuation occur, without power conversion losses. In the UPS mode, the system provides sinusoidal voltage at the fundamental value, $220 \mathrm{~V} / 60 \mathrm{~Hz}$, for the load during abnormal utility power conditions or grid failure.

A VCVSI performs the same as a voltage source and maintains voltage support for the load in the absence of a grid. Figure 2 shows a simplified, equivalent schematic diagram of a parallel processing UPS using a VCVSI. In the following analysis, it is assumed that the output low pass L-C filters of VCVSI will filter out high-order harmonics generated by PWM. The decoupling inductor is an essential part of any VCVSI, as it makes power flow control possible.

Assuming the maximum permissible voltage fluctuation in the gird voltage, $\mathrm{V}_{\mathrm{g}}$, is $\pm 6 \%$ at $220 \mathrm{~V} \pm 13 \mathrm{~V}$ and the load voltage, $V_{\text {load }}=V_{c}$, is kept at a constant $220 \mathrm{~V}$, then the decoupling inductor voltage, $V_{\mathrm{x}}$, of Figure 2 can be expressed as (1)

$$
V_{x}=V_{g} \angle 0-V_{c} \angle \delta
$$

where, $\mathrm{V}_{\mathrm{g}}$ and $\mathrm{Vc}$ are the grid and the inverter fundamental voltages, respectively. In steady state condition, the current flow from the grid through the decoupling inductor can be expressed as (2)

$$
I_{g}=\frac{V_{x}}{j X_{m}}
$$

where, $I_{g}$ is the fundamental gird current and $X_{m}$ is the decoupling inductor impedance. Using Equation (1) and (2), the grid current can be rewritten as (3)

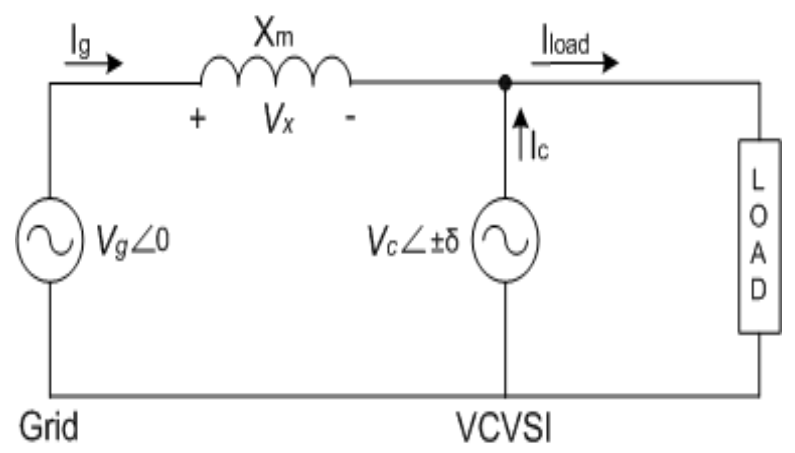

Figure 2. The equivalent circuit diagram of a parallel processing UPS. 


$$
I_{g}=\frac{V_{g} \angle 0-V_{c} \angle \delta}{j X_{m}}=-\frac{V_{c} \sin \delta}{X_{m}}-j \frac{V_{g}-V_{c} \cos \delta}{X_{m}}
$$

Using the per unit values $\mathrm{S}_{\text {base }}=\mathrm{V}_{\text {base }}^{2} / \mathrm{Z}_{\text {base }}, \mathrm{V}_{\text {base }}=\mathrm{V}_{\mathrm{c}}$ and $Z_{\text {base }}=X_{m}$, where $V_{\text {base }}, Z_{\text {base }}$ and $S_{\text {base }}$ are the base voltage, impedance, and apparent power values, respectively. The apparent power of the grid, inverter and decoupling inductor are given by:

$$
\begin{gathered}
S_{g p u}=P_{g p u}+j Q_{g p u}=-V_{g p u} \sin \delta+j\left(V_{g p u}^{2}-V_{g p u} \cos \delta\right) \\
S_{c p u}=P_{c p u}+j Q_{c p u}=-V_{g p u} \sin \delta+j\left(V_{g p u} \cos \delta-1\right) \\
S_{x p u}=j Q_{x p u}=j\left(V_{g p u}^{2}-2 V_{g p u} \cos \delta+1\right)
\end{gathered}
$$

where $S_{\text {gpu }}, S_{\text {cpu }}$ and $S_{\text {xpu }}$ are per unit values of the grid, inverter and decoupling inductor's apparent power respectively, and $\mathrm{V}_{\mathrm{gpu}}$ is the per unit value of the grid voltage

The phase angle could be both lagging or leading, providing either active power flow from the grid to the VCVSI, or vice versa. In the lagging phase case, active power flows from the grid toward the load. The higher phase angle results in more active power supply to the load or inverter from the grid. It means that the proposed system can be providing bi-directional power flow, both charging and discharging, between the battery and the AC side by controlling the phase angle. Therefore, in charging mode, the active power flow from the grid is expressed as (7)

$$
P_{g}=P_{\text {load }}+P_{b a t}
$$

where, $\mathrm{P}_{\mathrm{g}}$ and $\mathrm{P}_{\text {load }}$ are active power the grid and the load, respectively, $\mathrm{P}_{\mathrm{bat}}$ is charging power flow to the battery.

In the charging mode, power angle can be calculated as (8)

$$
\delta=\sin ^{-1}\left[-\frac{\left(P_{\text {load }}+P_{\text {bat }}\right) X_{m}}{V_{g} V_{c}}\right]
$$

From equation (8), when the required charging power is increased, the phase angle is increased. When the battery is fully charged, the phase angle is decreased.

\section{Simulation and Experimental Results}

\subsection{Simulation Results}

A PSim simulator was used to verify the operation of the proposed system. The operation characteristics are analyzed in the normal mode and the UPS mode. Nonlinear and variation load conditions for the simulation are 1KVA load capacity. Table 1 illustrates the simulation condition and parameter values.

The simulation was conducted to evaluate the performance of the proposed system in the presence of different operation modes. $\mathrm{V}_{\mathrm{g}}, \mathrm{V}_{\mathrm{c}}$ and $\mathrm{V}_{\text {load }}$ are the voltage waveforms of the grid, inverter and load, and $\mathrm{I}_{\mathrm{g}}, \mathrm{I}_{\mathrm{c}}$ and $\mathrm{I}_{\text {load }}$ are current waveform of the grid, inverter and load, respectively. $\mathrm{P}_{\text {load }}$ is the active power waveform of the load. The waveform of the normal operation mode at nonlinear load and a crest factor of 3 is shown in Figure. 3

Figure 3 indicates that the VCVSI can mitigate the harmonic current of a nonlinear load demand and the grid supplies the remaining active power. In normal mode, the VCVSI prevents any lower order harmonics from being injected into the grid. The harmonic spectrum of the load voltage, grid current, load current and VCVSI current with the nonlinear load, as shown in Figure 4.

As shown Figure 4, the reactive power associated with low order harmonics from the nonlinear load of ITHD: $62.7 \%$ could be supplied by the VCVSI. It is shown that the proposed system satisfies THD, grid ITHD: $1.1 \%$, requirements of voltage and current for the full range of the load.

The waveform of the charging mode under nonlinear load conditions is shown in Figure 4. $\mathrm{P}_{\mathrm{g}}$ and $\mathrm{P}_{\mathrm{c}}$ are the active power waveforms of the grid and the VCVSI, respectively.

Table 1. System parameters and specifications.

\begin{tabular}{cccc}
\hline Parameter & Value & Parameter & Value \\
\hline Vac & $220[$ Vrms $]$ & Vdc(battery) & $200 \mathrm{~V}$ \\
Frequency & $60 \mathrm{~Hz}$ & Fsw & $10 \mathrm{kHz}$ \\
Full load & $1 \mathrm{KVA}$ & Lm & $42 \mathrm{mH}$ \\
$\delta_{\max }$ & $20^{\circ}$ & Transformer & $1: 2$ \\
\hline
\end{tabular}

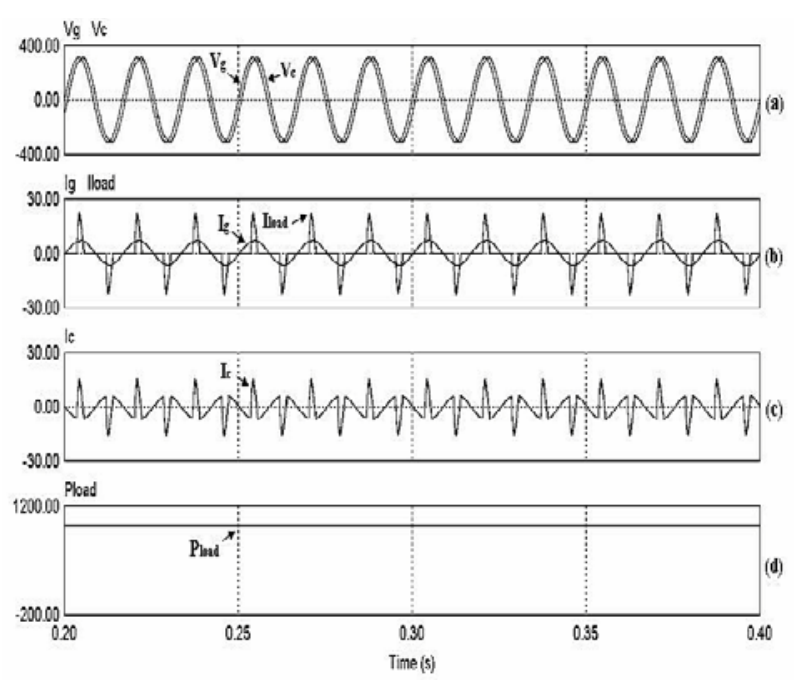

Figure 3. Waveforms of normal mode at nonlinear load condition. (a) Voltage of grid and inverter. (b) Current of grid and load. (c) Inverter current. (d) Load active power. 
As indicated in Figure 5, the grid should be the active power supply of $500 \mathrm{~W}$ required from the load when in normal mode, such as Figure 3. If the required charging power input to the battery is increased, the proposed system controls the phase angle between the grid and the VCVSI. The increased phase angle results in more active power supply from the grid, $500 \mathrm{~W}$ to $1 \mathrm{KW}$, to the load and VCVSI. The harmonic spectrum of the load voltage, grid current, load current and VCVSI current with the nonlinear load during charging operation is shown in Figure 6. It shows that the proposed system can mitigate low order harmonics of the load voltage and current in order to meet IEEE standards in the presence of nonlinear loads in both normal and charging modes.

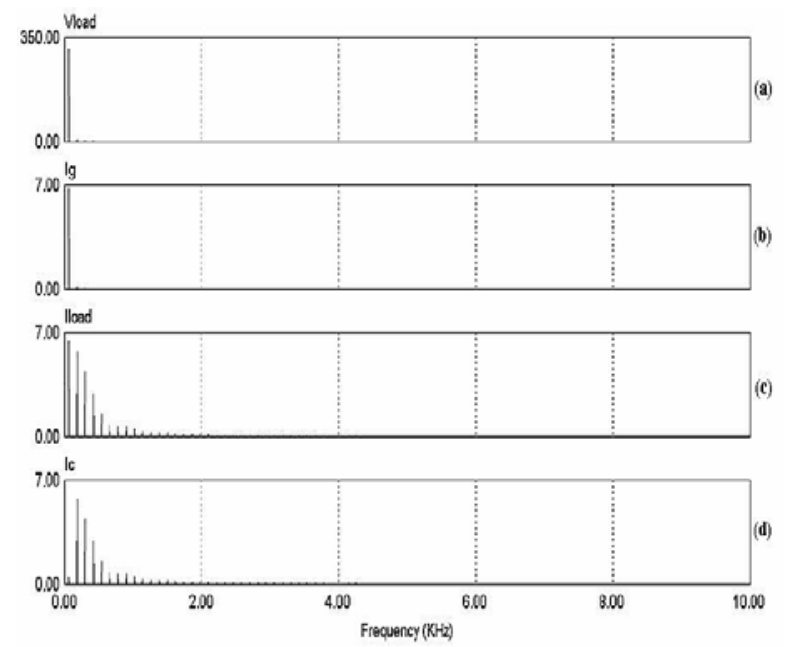

Figure 4. The harmonic spectrum analysis when normal mode. (a) Load voltage (b) Grid current. (c) Load current. (d) Load active power.

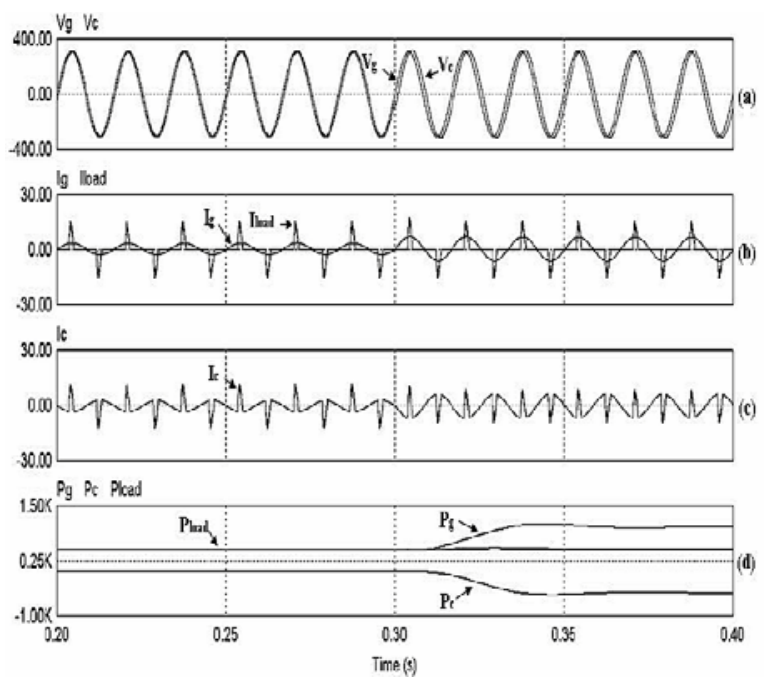

Figure 5. Waveforms of charging operation mode at nonlinear load condition. (a) Voltage of grid and inverter. (b) Current of grid and load. (c) Inverter current. (d) Active power of gird, inverter and load.

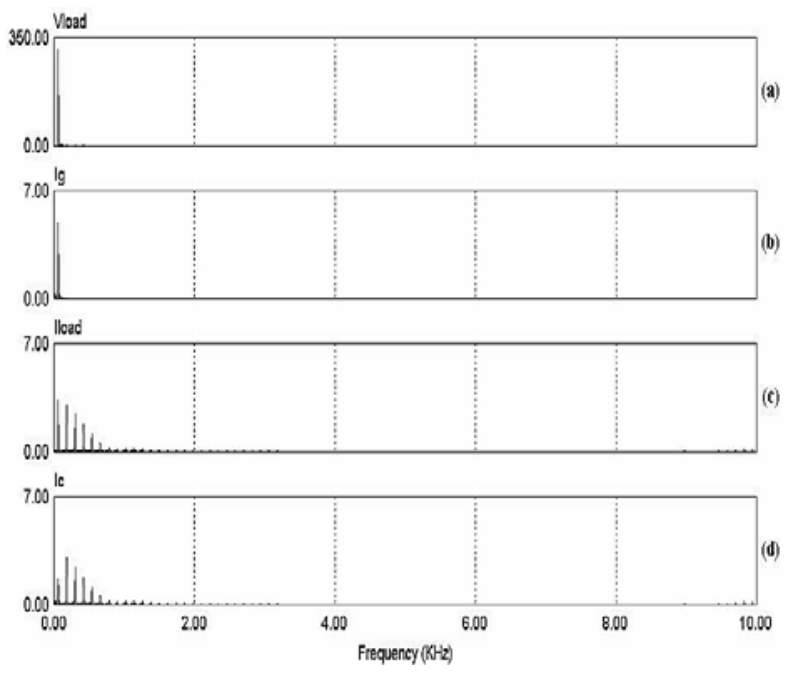

Figure 6. The harmonic spectrum analysis when the charging operation mode. (a) Load voltage. (b) Grid current. (c) Load current. (d) Inverter current.

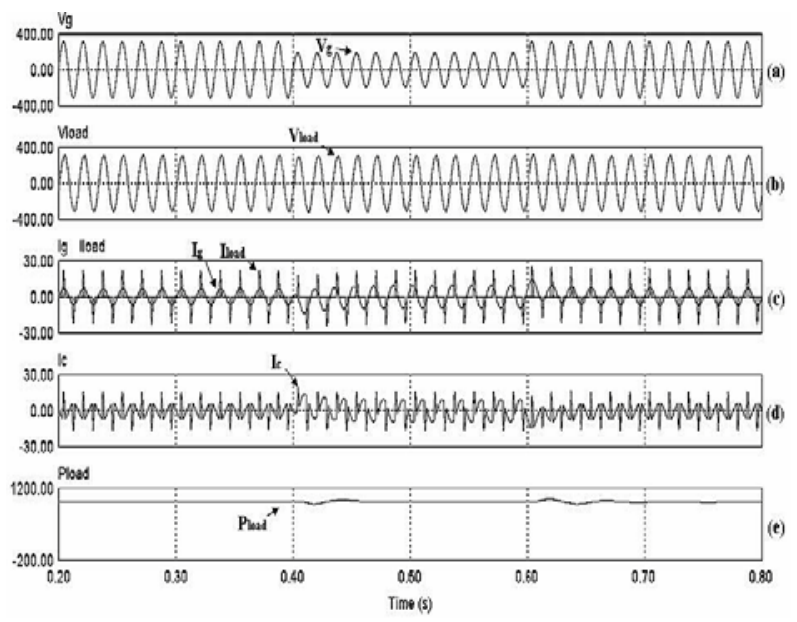

Figure 7. The operation waveforms of voltage stabilization when voltage sag. (a) Grid voltage. (b) Load voltage. (c) Current of grid and load. (d) Inverter current. (e) Load active.

Figure 7 and 8 shows the performance of the proposed system during voltage stabilization in the presence of nonlinear load conditions. In this simulation, the grid voltage is changed from its nominal value of $220 \mathrm{~V}$ to $132 \mathrm{~V}$, during voltage sag, and to 308, during voltage swell. Figure 7 shows that the simulation results during normal mode, where the grid voltage changes from RMS value of $220 \mathrm{~V}$ to $132 \mathrm{~V}$ for period 12 at $20 \mathrm{~ms}$ and, returning to $220 \mathrm{~V}$. In Figure 8, the grid voltage changes form an RMS value of $220 \mathrm{~V}$ to $308 \mathrm{~V}$ for the same situation shown in Figure 7. The system mitigates the harmonic current of a nonlinear load demand and the grid supplies the remaining active power, as in Figure 3, during a sudden voltage change. The proposed system picks up the load rapidly after sudden voltage changes. 
The load voltage is maintained at $220 \mathrm{~V}, \pm 1.2 \%$ voltage regulation, and is unaffected by the sudden voltage sag and voltage swell. This means that the proposed system meets the IEEE standard of less than 5\% of THD and voltage regulation within $\pm 5 \%$, for the whole control range

Figure 9 shows that the simulation results in the UPS mode during nonlinear load conditions. It assumes that at 30ms the grid fails and the VCVSI has to supply the load. As shown, before grid failure the system supplies the reactive power demanded by the nonlinear load and rapidly picks up the load after grid failure.

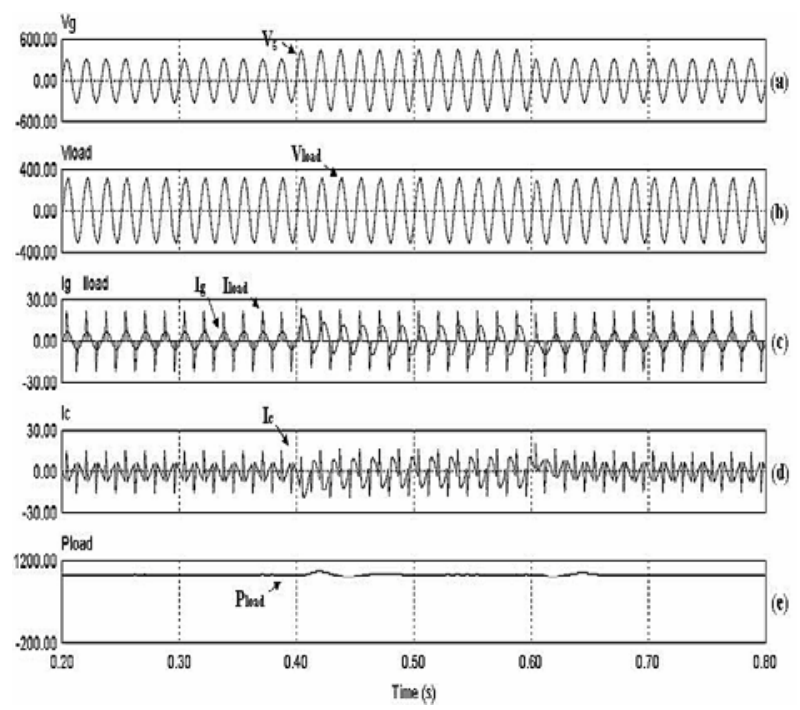

Figure 8. The operation waveforms of voltage stabilization when voltage swell. (a) Grid voltage. (b) Load voltage. (c) Current of grid and load. (d) Inverter current. (e) Load active power.

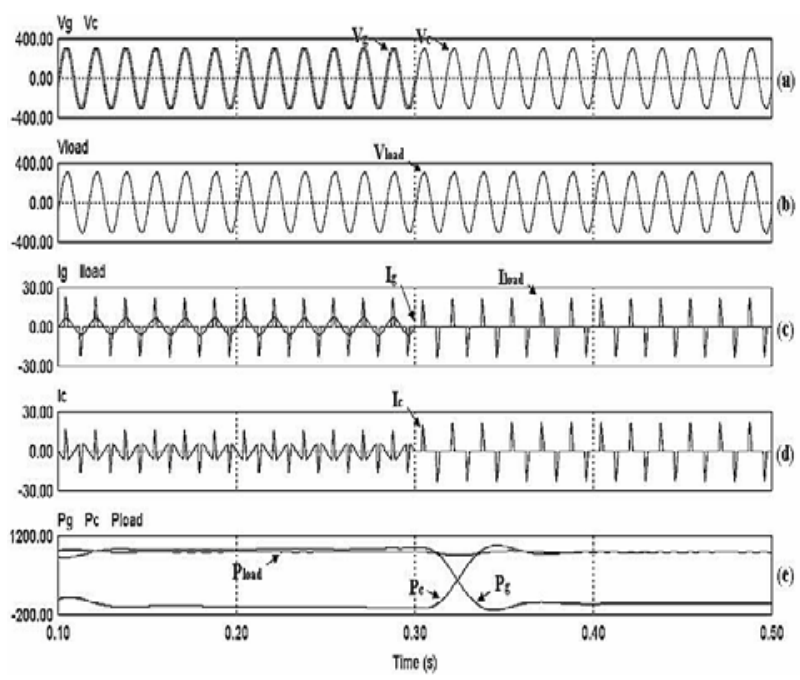

Figure 9. The operation waveforms of voltage stabilization when voltage sag. (a) Grid voltage. (b) Load voltage. (c) Current of grid and load. (d) Inverter current. (e) Load active.

\subsection{Experimental Results}

In order to confirm the above mentioned simulation results pertaining to system performance, the prototype proposed system(1KVA) for the experiment was constructed to be identical to the simulation parameters and the operating condition with the simulation. The scope and power analyzers were used to record the information for further evaluative comparisons of the analytical and simulation results. The digital scope (TDS3054B) was used to capture the following results.

The experimental waveform of the normal mode at nonlinear load condition is shown in Figure 10. In Figure 10, Ch 1 and Ch2 are the voltage waveforms of the grid and inverter, and $\mathrm{Ch} 3$ and Ch4 are the current waveforms of the load and grid, respectively. Figure 10 indicates that the VCVSI can mitigate the harmonic current of a nonlinear load demand and the grid supplies the remaining active power. In normal mode, the VCVSI prevents any lower order harmonics from being injected into the grid. This results support the simulation results (Figure 3).

Figure 11 presents the current harmonic spectrum of the gird current and load current from zero to $5[\mathrm{kHz}]$. The Tektronix (TDS3054B) digital scope already has a FFT module. As shown Figure 12, all the reactive power associated with low order harmonics from the nonlinear load (load current THD: 63.2\%) could be supplied by the VCVSI. It is shown that the proposed system can achieve satisfies THD (grid current THD:3.1\%) requirements of voltage and current for the full range of the load.

Voltage stabilization would be one of the most important requirements in power management systems. The following tests were carried out in order to confirm the performance of the proposed system in stabilizing the

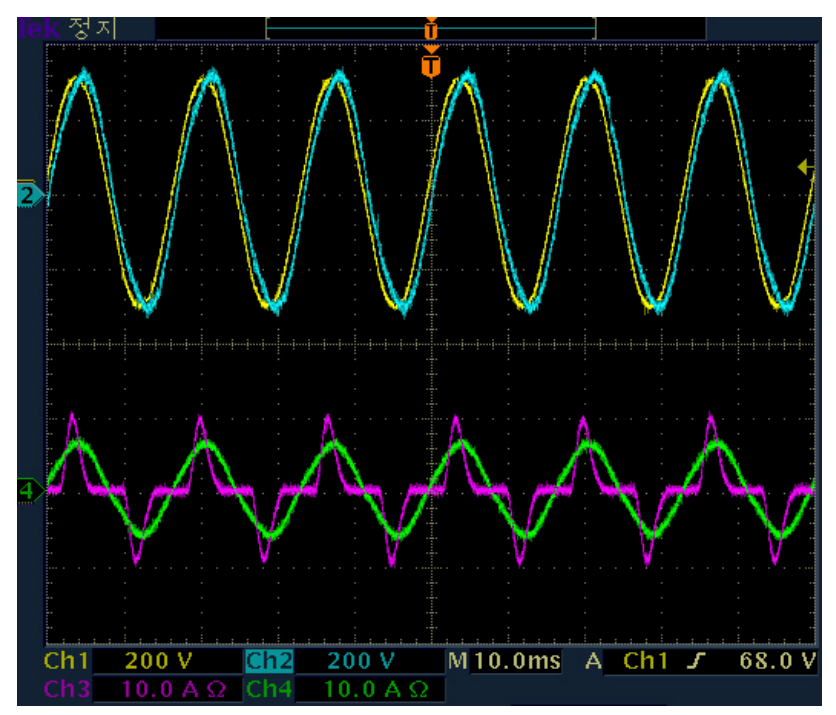

Figure 10. Experimental results of the normal operation mode at nonlinear load condition. 
load voltage. Figure 12 shows that the experimental results during normal mode, where the grid voltage changes from RMS value of $220 \mathrm{~V}$ to $160 \mathrm{~V}$ for 0.5 second and, returning to $220 \mathrm{~V}$. The proposed system can mitigates the harmonic current of a nonlinear load demand and the grid supplies the remaining active power, as in Figure 10, during a sudden voltage change. As shown Figure 12, the load voltage is maintained at $220 \mathrm{~V}$, less than $\pm 2 \%$ voltage regulation, and is unaffected by the sudden voltage change. It is shown that the proposed system can maintain the load voltage regardless of changes in the grid voltage. Figure $\mathbf{1 3}$ shows that the experimental results in the UPS mode during nonlinear load conditions. In Figure 13, Ch1 and Ch2 are the voltage waveforms of the load inverter and load, and Ch3 and $\mathrm{Ch} 4$ are the current waveforms of the load and grid, respectively.

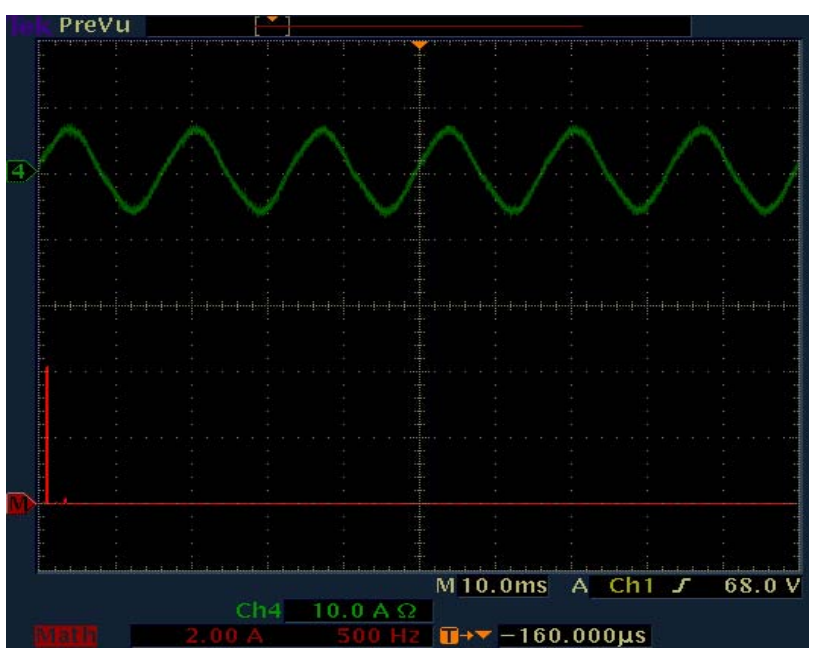

(a)

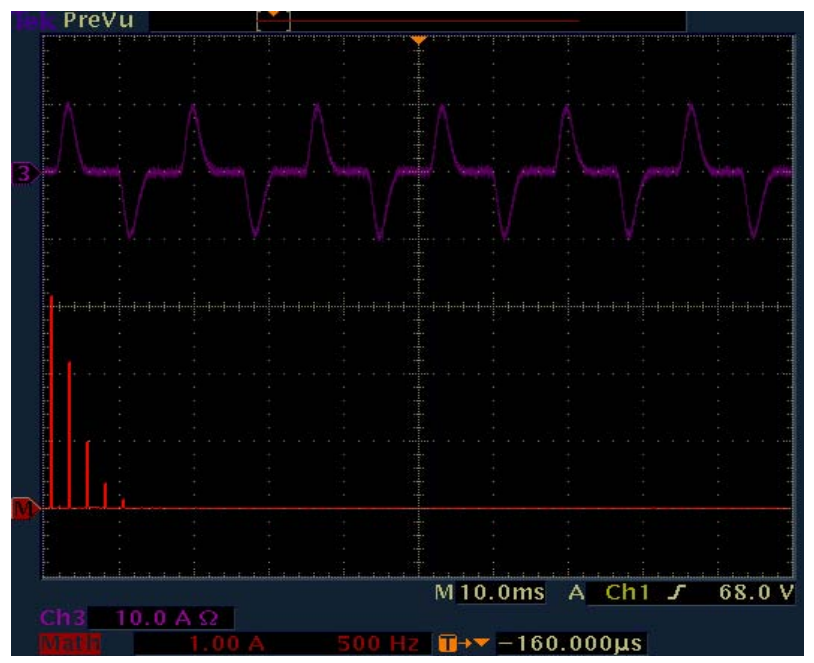

(b)

Figure 11. The harmonic spectrum analysis of the proposed system at nonlinear load condition. (a) Grid current. (b) Load current.

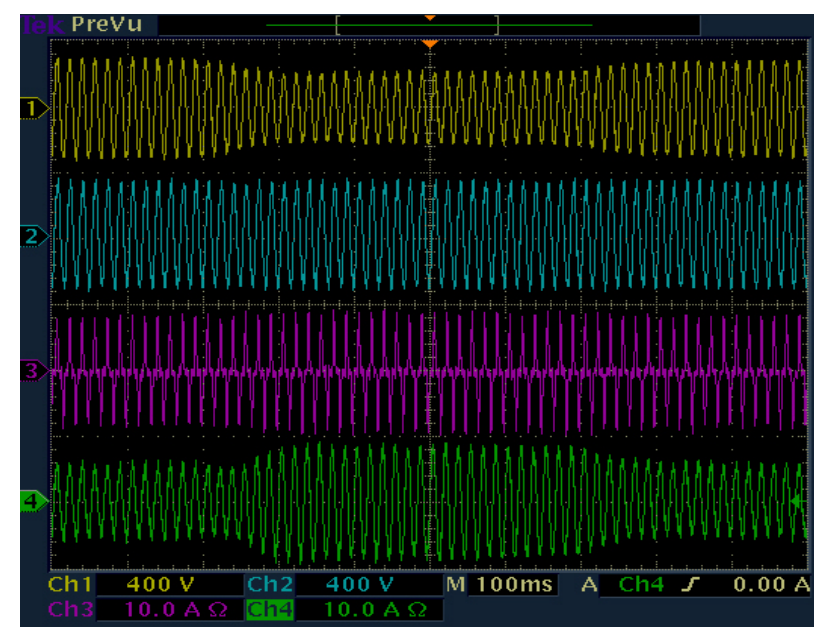

Figure 12. Experimental results of the proposed system when sudden voltage changes.

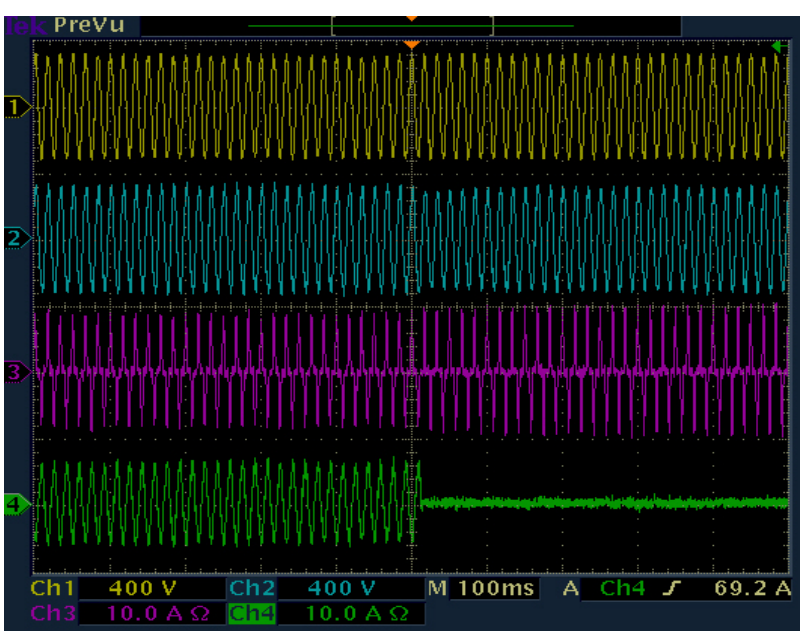

Figure 13. 14 Experimental results of the UPS operation mode for state an transient response at nonlinear load condition.

As shown Figure 13, the proposed system can supply and maintain the pure sinusoidal voltage waveform when the gird fails in the presence of nonlinear loads. And also VCVSI can mitigate low order harmonics during the whole control range. These results also comply with simulation results (Figure 7 and Figure 9). Figure 14 presents the voltage harmonic spectrum of the load voltage from zero to $5[\mathrm{kHz}]$.

\section{Conclusion}

This paper addressed parallel processing UPS using a single phase bi-directional VCVSI for sudden voltage fluctuation in power management. To reduce the complexity, cost and number of power conversions and improve efficiency, only one VCVSI was used. It was demonstrated that the system performs well in either the normal or UPS mode of operation. In the normal mode, 


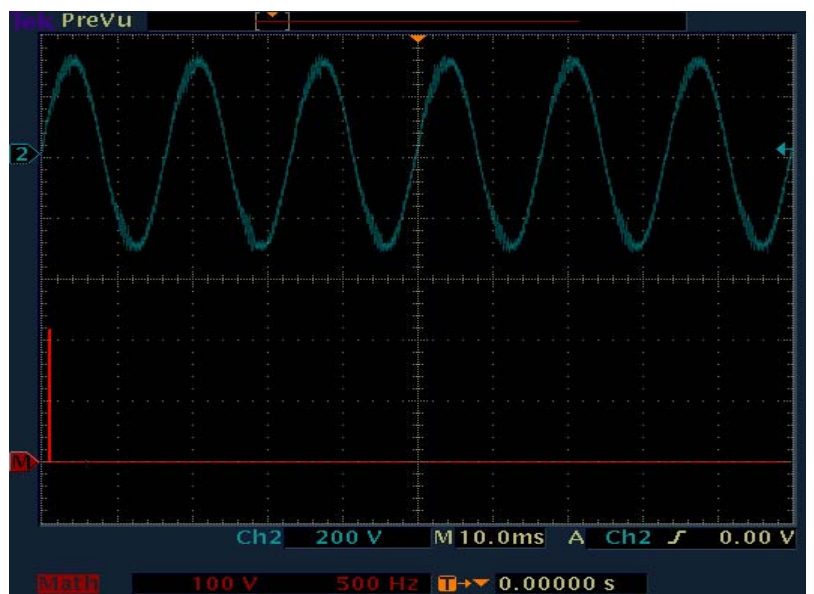

Figure 14. The harmonic spectrum analysis of the proposed system when UPS operation mode.

the VCVSI operates to compensate the current harmonic and the reactive power demand of nonlinear or variable loads. The system controlled and provided voltage stabilization for the load when sudden voltage sag and swell occurred. In the UPS mode, the proposed system supplied sinusoidal voltage at the fundamental value for the load during an abnormal utility power condition. It was shown that the proposed system protected the system from outages by an abnormal utility power conditions and sudden voltage fluctuations and changes. The detailed simulation and experimental results verified the performance system theory and its capacity to satisfy the IEEE recommended requirements for electric power quality.

\section{Acknowledgements}

This work was supported by the New \& Renewable Energy (No. 20123021020010) of the Korea Institute of Energy Technology Evaluation and Planning (KETEP) grant funded by the Korea government Ministry of Knowledge Economy.

\section{REFERENCES}

[1] H. Deng, R. Oruganti, and D. Srinivasan, "Modeling and Control of Single-Phase UPS Inverter: A Survey”, 2005 PEDS Conf. Power electronics and Drives Systems, vol. 2, pp. 848-853, Nov. 2005.

[2] S. Karve, "Three of a Kind[UPS topologies, IEC standard],” IEE Review, vol. 48, no. 2, pp. 27-31, March.

[3] B. H. Kwon, J.H. Choi, and T.W. Kim, "Improved Single-Phase Line-Interactive UPS,” IEEE Trans. Ind. Electron., vol. 48, no. 4, Aug. 2001.

[4] W. J. Ho, J.B. Lio and W.S. Feng, "Economic UPS structure with phase-controlled battery charger and input-power-factor improvement," IEE Proc. Eletr. Power Appl., vol. 144, no. 4, pp. 221-226, July 1997.

[5] J. C. Wu and H.K. Jou, "A New UPS Scheme Provides Harmonics Suppression and Input Power Factor Correction”, IEEE Trans. Ind. Electr., Vol. 42, No. 6, pp. 629-636, Dec. 1995.

[6] Monitoring Electric Power Quality, IEEE Standard 1159, 1995. IEEE Standard Board.

[7] The Application and Testing of Uninterruptible Power Supplies for Power Generating Stations, ANSI/IEEE Standard 944, 1985.

[8] M. Ashari, W.W.L. Keerthipala, and C.V. Nayar, “ A single phase parallel connected uninterruptible power supply/demand side management system”, IEEE Trans. Energy Convers., vol. 15, no. 1, pp. 97-102, Mar. 2000.

[9] Soren Rathmann and Henry A. Warnerr, "New generation ups technology, The delta conversion principle”, IAS 96, Conference Record of the 1996 IEEE, Vol. 4, pp. 2389-2395, 1996

[10] S.H. Ko, S.R. Lee, H. Dehbonei, and C.V. Nayar, “Application of Voltage and Current Controlled Voltage Source Inverters for Distributed Generation Systems," IEEE. Trans. Energy Conver., vol. 21, no. 3, pp. 782-792, Sept. 2006

[11] S.H. Ko, , S.R. Lee, C.V.Nayar and C.Y Won, ”Design Considerations for a Distributed Generation System Using a Voltage-Controlled Voltage Source Inverter,” Journal of Power Electronics, vol. 9, no.4, pp. 643-653, July 2009 